\title{
Sensibilidade de valores genéticos de codornas de corte em crescimento às modificações de níveis de proteína das dietas
}

[Sensitivity of genetic values of growing meat-type quails to changes in protein levels of diet]

\author{
G.G. Santos ${ }^{1,4}$, G.S.S. Corrêa ${ }^{2}$, B.D. Valente ${ }^{1,4}$ M.A. Silva ${ }^{3,4^{*}}$, A.B. Corrêa ${ }^{1,4}$, \\ V.P.S. Felipe ${ }^{1,4}$, R.R. Wenceslau ${ }^{1,4}$ \\ ${ }^{1}$ Aluno de pós-graduação - EV-UFMG - Belo Horizonte, MG \\ ${ }^{2}$ Aluna de pós-doutorado - EV-UFMG - Belo Horizonte, MG \\ ${ }^{3}$ Escola de Veterinária - UFMG \\ Caixa Postal 567 \\ 30123-970 - Belo Horizonte, MG \\ ${ }^{4}$ Bolsista do $\mathrm{CNPq}$
}

\begin{abstract}
RESUMO
Um total de 5240 informações de peso de progênies provenientes de 200 reprodutores e 400 reprodutrizes, alimentadas com dietas com níveis de proteína bruta que variaram de 24 a 30\%, e nível de $2900 \mathrm{kcal}$ de energia metabolizável, foi utilizado para avaliar a sensibilidade de valores genéticos de duas linhagens de codornas de corte, EV1 e EV2, em relação às mudanças de níveis protéicos das dietas, utilizando-se modelos de regressão aleatória. As codornas com maior valor genético aditivo para peso no ambiente médio (nível protéico igual a zero em uma escala de -1 a 1) respondem de maneira positiva ao aumento do nível protéico da dieta, sendo mais importante para a linhagem EV2 e de pouca expressão para a linhagem EV1, no $21^{\circ}$ dia de idade. No $42^{\circ}$ dia de idade, codornas da linhagem EV1 apresentam aumento de dispersão dos valores genéticos com o aumento dos níveis protéicos da dieta, indicando heterogeneidade de sensibilidades dos valores genéticos aditivos à mudança ambiente, ou à existência de interação genótipo x ambiente. Codornas EV2 apresentaram aumento de dispersão dos valores genéticos em função do nível protéico em ambas as idades. A interação genótipo $\mathrm{x}$ nível protéico interfere em menores idades na expressão fenotípica da linhagem EV2. As herdabilidades estimadas apresentaram alta variação e maior magnitude para maiores níveis de proteína bruta na dieta, indicando maior resposta à seleção para níveis mais elevados de proteína da dieta, à exceção da linhagem EV1, no $21^{\circ}$ dia de idade. Avaliações genéticas realizadas para codornas alimentadas com dietas contendo determinado nível protéico não permitiriam a predição de valores genéticos válidos para outros níveis protéicos das dietas, à exceção da linhagem EV1, no $21^{\circ}$ dia de idade.
\end{abstract}

Palavras-chave: codorna de corte, norma de reação, interação genótipo x ambiente

\section{ABSTRACT}

A total of 5,240 body weight records of quail of offsprings from 200 males and 400 females matings, fed crude protein diet levels varying from 24 to $30 \%$ and 2,900kcal of metabolizable energy, was used to evaluate the sensitivity of genetic values of two meat strains, EV1 and EV2, to changes in crude protein levels of diets, using random regression models. Quails showing higher body weight genetic value in the average environment (crude protein level equal to zero in a scale varying from -1 to 1) respond positively to an increase in crude protein level of diet, this change is more important for EV2 quails (higher slope) and of small magnitude for EV1 quails at 21 days of age. EV1 quails at 42 days of age showed remarked increase in the dispersion for breeding values as crude protein level increased in the diets, suggesting heterogeneity of slope of the breeding values to change in protein level of diets or suggesting a genotype $x$ protein level of diet interaction. EV 2 quails showed an increase in the breeding values in function of crude protein level of diet for both ages. Genotype $x$ protein level of diet interferes earlier in the phenotype expression of EV2 quails. Heritability estimates showed a sizeable variation and were of higher values for quails fed higher protein level diets, except

Recebido em 13 de novembro de 2007

Aceito em 1 de setembro de 2008

* Autor para correspondência (corresponding author)

E-mail: martinho@vet.ufmg.br 
for EV1 quails at 21 days of age. Genetic evaluations of quails fed specific crude protein level do not allow a prediction of valid breeding values for quails fed other crude protein level of diet.

Keywords: meat-type quail, reaction norm, genotype $x$ environment interaction

\section{INTRODUÇÃO}

Modelos clássicos de avaliação genética atribuem a cada animal um valor genético válido para qualquer ambiente. Isso nem sempre é verdadeiro, pois, para determinadas características, pode ocorrer heterogeneidade de variância genética ou modificações na ordem de classificação dos valores genéticos estimados para os diferentes ambientes. A modificação na variância genética ou na ordem de classificação dos valores genéticos em função do ambiente caracteriza a interação genótipo $\mathrm{x}$ ambiente que pode resultar em desempenhos para o ambiente de produção diferentes em relação ao predito com base em avaliação genética realizada em ambiente de seleção (Falconer, 1989).

Parâmetros genéticos de peso corporal em codornas foram estimados para diferentes idades por intermédio de abordagens multicaracterísticas (Saatci et al., 2006) e modelos de regressão aleatória em função da idade (Akbas et al., 2004; Dionello et al., 2006). Porém, não há estudos na literatura sobre a heterogeneidade contínua destes parâmetros, ou sobre a heterogeneidade de sensibilidades de valores genéticos aditivos preditos, decorrentes da modificação gradual do ambiente, o que caracteriza interação genótipo $\mathrm{x}$ ambiente.

Dentre os fatores de ambiente, nos sistemas de produção de codornas de corte, os níveis protéicos da dieta se destacam. A proteína é o nutriente mais caro da dieta de codornas de corte (Corrêa et al., 2007b), sendo responsável por considerável parte do custo de programas de seleção (Ferreira et al., 2004).

Uma estratégia para diminuir esse custo seria utilizar dietas com níveis de proteína bruta abaixo daquele que maximiza a produção ou o lucro. Porém, essa estratégia só resulta em predições de valores genéticos válidos para dietas com diferentes níveis protéicos se houver homogeneidade de sensibilidades dos valores genéticos de diferentes indivíduos à modificação do nível de proteína bruta da dieta.

A interação genótipo $\mathrm{x}$ ambiente pode ser analisada por intermédio de modelos de regressões aleatórias, nos quais o valor genético de cada animal avaliado é considerado como função do ambiente (Kolmodin et al., 2002). Essa abordagem possibilita a predição e a comparação dos valores genéticos e a estimação da variância genética para qualquer ambiente dentro de um intervalo definido, mesmo na presença de heterogeneidade de variância e de sensibilidades de valores genéticos à modificação do ambiente.

A existência de heterogeneidade de sensibilidades genéticas ao nível protéico da dieta indicaria, para a maximização do potencial genético, que os programas de seleção devem ser realizados para nível específico de proteína da dieta.

No Brasil, existem diversas pesquisas que visam estabelecer o desempenho máximo de codornas de linhagens específicas quanto aos níveis protéicos da dieta (Fridrich et al., 2005; Corrêa et al., 2005; Corrêa et al., 2007a, b, c), quanto aos níveis de aminoácidos sulfurosos, metionina + cistina (Corrêa et al., 2006), e de lisina (Corrêa et al., 2007d) e da interação genótipo específico versus nível nutricional da dieta (Valente et al., 2006). Nenhum trabalho foi realizado para avaliar o desempenho de progênies de diferentes reprodutores alimentadas com diferentes níveis protéicos, principalmente no que se refere ao estudo da interação genótipo x ambiente, cujos resultados pudessem subsidiar programas de seleção de codornas de corte.

Assim, o objetivo deste estudo foi, por intermédio de modelos de regressões aleatórias, investigar a presença de interação genótipo x nível de proteína da dieta no peso ao $21^{\circ}$ e $42^{\circ}$ dias de idade, em duas linhagens de codornas de corte.

\section{MATERIAL E MÉTODOS}

As informações de codornas de corte utilizadas nestas análises são provenientes de experimentos realizados no setor de coturnicultura da Escola de Veterinária da UFMG. Progênies de 100 reprodutores e 200 reprodutrizes foram alimentadas com dietas com níveis de proteína que variaram de 24 a $30 \%$, e nível de $2900 \mathrm{kcal}$ de energia metabolizável (Tab. 1). 
Tabela 1. Composição das dietas experimentais de codornas alimentadas com dietas únicas do nascimento ao $42^{\circ}$ dia de idade

\begin{tabular}{lrrrr}
\hline \multirow{2}{*}{\multicolumn{1}{c}{ Ingrediente (\%) }} & \multicolumn{4}{c}{ Nível de proteína bruta (\%) } \\
\cline { 2 - 5 } & 24 & 26 & 28 & 30 \\
\hline Milho & 46,862 & 40,640 & 33,812 & 27,280 \\
Farelo de soja & 42,087 & 47,461 & 53,112 & 58,620 \\
Farelo de trigo & 4,000 & 4,000 & 4,000 & 4,000 \\
Óleo de soja & 3,736 & 4,715 & 5,871 & 6,941 \\
Calcário & 1,086 & 0,998 & 1,041 & 1,018 \\
Fosfato bicálcico & 0,924 & 0,921 & 0,867 & 0,839 \\
Suplem. min. e vit. ${ }^{1}$ & 0,500 & 0,500 & 0,500 & 0,500 \\
Sal comum & 0,266 & 0,236 & 0,256 & 0,251 \\
DL-metonina & 0,138 & 0,193 & 0,229 & 0,275 \\
L-treonina & 0,102 & 0,136 & 0,162 & 0,195 \\
Inerte & 0,300 & 0,200 & 0,150 & 0,080 \\
\hline Total & 100,00 & 100,00 & 100,00 & 100,00 \\
\hline Composição calculada & & & & \\
\hline Proteína bruta (\%) & 24,00 & 26,00 & 28,00 & 30,00 \\
En. metab. (kcal/kg) & 2900 & 2900 & 2900 & 2900 \\
Cálcio (\%) & 0,80 & 0,80 & 0,80 & 0,80 \\
Fósf disponível (\%) & 0,30 & 0,30 & 0,30 & 0,30 \\
Met.+ cist. (\%) & 0,87 & 0,99 & 1,05 & 1,14 \\
Metionina (\%) & 0,60 & 0,68 & 0,74 & 0,81 \\
Lisina (\%) & 1,31 & 1,48 & 1,59 & 1,73 \\
Treonina (\%) & 1,02 & 1,13 & 1,24 & 1,35 \\
\hline Cón (\%) & & & & \\
\hline
\end{tabular}

${ }^{T}$ Composição por quilo= vit $\mathrm{A}: 2.000 .000 \mathrm{UI}$; vit $\mathrm{D}_{3}: 375.000 \mathrm{UI}$; vit $\mathrm{E}: 3.750 \mathrm{mg}$; vit $\mathrm{k}_{3}$ : $500 \mathrm{mg}$; vit $\mathrm{B}_{1}$ : $250 \mathrm{mg}$; vit $\mathrm{B}_{2}$ : $750 \mathrm{mg}$; vit $\mathrm{B}_{6}: 500 \mathrm{mg}$; vit $\mathrm{B}_{12}: 3.750 \mathrm{mcg}$; niacina: $6.250 \mathrm{mg}$; ac. Pantotênico: $2.500 \mathrm{mg}$; biotina: 10mg; ac. Fólico: 125mg; colina: $75.000 \mathrm{mg}$; selênio: $45 \mathrm{mg}$; iodo: $175 \mathrm{mg}$; ferr: $12.525 \mathrm{mg}$; cobre: $2.500 \mathrm{mg}$; manganês: $19.500 \mathrm{mg}$; zinco: $13.750 \mathrm{mg}$; avilamicina: $15.000 \mathrm{mg}$; narasin: $12.250 \mathrm{mg}$; B.H.T.: $500 \mathrm{mg}$; vit C: $12.500 \mathrm{mg}$.

O conjunto de dados constituiu-se de pesagens realizadas no $21^{\circ} \mathrm{e} 42^{\circ}$ dia de idade em codornas de corte de duas linhagens distintas: EV1 e EV2. A descrição dos arquivos de dados encontra-se na Tab. 2. O banco de dados, após descarte de observações de codornas cujo sexo não foi identificado e que apresentaram peso maior ou menor que três desvios-padrão em relação ao peso médio das codornas em cada idade, continha a identificação do animal, pai, mãe, sexo, pesos das codornas no $21^{\circ}$ e $42^{\circ}$ dias de idade e nível de proteína bruta da dieta $(24,26$, 28 e $30 \%)$. Para fins de análises, as informações disponíveis foram divididas em quatro arquivos distintos, um para cada combinação de linhagem e idade.

Tabela 2. Descrição dos arquivos contendo pesos de codornas das linhagens EV1 e EV2 no $21^{\circ}$ e $42^{\circ}$ dias de idade

\begin{tabular}{lcccc}
\hline & \multicolumn{3}{c}{ EV1 } & \multicolumn{2}{c}{ EV2 } \\
\cline { 2 - 5 } & 21 dias & 42 dias & 21 dias & 42 dias \\
\hline Número de observações & 1467 & 1432 & 1180 & 1161 \\
Número de observações $(24 \% \mathrm{~PB})$ & 600 & 605 & 516 & 520 \\
Número de observações $(26 \% \mathrm{~PB})$ & 182 & 163 & 91 & 92 \\
Número de observações $(28 \% \mathrm{~PB})$ & 383 & 388 & 190 & 195 \\
Número de observações $(30 \% \mathrm{~PB})$ & 302 & 276 & 383 & 354 \\
Animais incluídos na matriz de parentesco & 1842 & 1812 & 1455 & 1440 \\
\hline
\end{tabular}


O nível de proteína bruta da dieta $i$, transformado para uma escala de -1 a 1 , foi obtido da seguinte maneira:

$i=-1+2\left(\frac{\text { nível de proteína bruta na dieta - menor nível protéico }}{\text { maior nível protéico - menor nível protéico }}\right)$

O modelo utilizado nas análises considerou os efeitos fixos de sexo e os aleatórios genéticos aditivos diretos como funções do nível de proteína bruta da dieta. Dessa maneira, para cada sexo e valor genético, foram atribuídos um conjunto de coeficientes de regressão específicos que representam o comportamento desses efeitos no intervalo entre $24 \%$ e $30 \%$ de proteína.

O mesmo modelo foi utilizado nas quatro análises que envolveram combinações de linhagem e peso, salvas em quatro arquivos. O modelo para análise dos dados é representado por:

$$
y_{h i j}=\sum_{k=0}^{1} b_{j k} x_{k}(i)+\sum_{k=0}^{1} a_{h k} x_{k}(i)+e_{h i j},
$$

que:

$y_{h i j}$ é a observação do animal $h$, do sexo $j$, alimentado com dieta de nível protéico $i ; b_{j k}$ é o coeficiente de regressão fixo $k$ atribuído ao sexo $j, a_{h k}$ é o coeficiente de regressão aleatório $k$ de efeito genético aditivo direto atribuído ao animal $h, x_{k}(i)$ é o polinômio natural $k$ atribuído ao nível protéico $i$ e $e_{h i j}$ é o resíduo associado à observação $y_{h i j}$, sendo este o único efeito que não foi considerado uma função do nível de proteína bruta da dieta.

O modelo em notação matricial foi descrito como:

$y=X b+Z a+e$, em que:

$y$ é o vetor de observações, $b$ é o vetor com coeficientes de regressão relativos aos efeitos fixos de sexo, $a$ é o vetor com coeficientes de regressão aleatória atribuídos ao efeito genético aditivo direto, $X$ e $Z$ são matrizes de incidência dos efeitos em $b$ e $a$, contendo polinômios naturais relativos ao nível de proteína bruta utilizado na observação; e é o vetor dos resíduos.

Considera-se, ainda, que:

$$
\begin{aligned}
& E(y)=X b \\
& G=\left[\begin{array}{cc}
\sigma_{b 0}^{2} & \sigma_{b 0 b 1} \\
\sigma_{b 0 b 1} & \sigma_{b 1}^{2}
\end{array}\right]
\end{aligned}
$$$$
V(y)=Z(A \otimes G) Z^{\prime}+I_{n} \sigma_{e}^{2}
$$$$
V\left[\begin{array}{l}
a \\
e
\end{array}\right]=\left[\begin{array}{cc}
A \otimes G & \phi \\
\phi & I_{n} \sigma_{e}^{2}
\end{array}\right], \text { em que: }
$$

$\sigma_{b_{0}}^{2}$ e $\sigma_{b_{1}}^{2}$ são componentes de variância atribuídas aos coeficientes de regressão constante e linear do efeito genético aditivo direto, $\sigma_{b_{0} b_{1}}$ é o componente de covariância entre os coeficientes de regressão constante e linear do efeito genético aditivo direto, $\sigma_{e}^{2}$ é o componente de variância residual, $A$ é a matriz de numeradores do coeficiente de parentesco de Wright e $n$ é o número de observações.

Os componentes de covariância atribuídos a cada efeito aleatório foram estimados por intermédio do programa REMLF90 (Misztal, 2001) que utiliza a maximização da esperança da função de máxima verossimilhança restrita (EMREML). O critério de convergência utilizado, definido pelo quadrado médio das diferenças entre soluções consecutivas, foi de $1 \times 10^{-11}$.

Após a obtenção de $G$, estimações das variâncias e covariâncias genéticas aditivas diretas para qualquer nível protéico ou combinação de níveis protéicos tornam-se possíveis e foram obtidas por meio de funções de covariância (Kirkpatrick et al., 1990). A partir dessas funções, obtém-se a estrutura de covariância genética aditiva direta em função do nível protéico da dieta. Assim, a covariância genética aditiva direta entre os níveis protéicos $i$ e $j\left(\sigma_{a_{i j}}\right)$ foi obtida por: 


$$
\begin{aligned}
& \sigma_{a_{i j}}=Z_{i} G Z_{j}^{\prime} ; \text { em que } \\
& Z_{i}=\left[\begin{array}{ll}
x_{o}(i) & x_{1}(i)
\end{array}\right] \\
& Z_{j}=\left[\begin{array}{ll}
x_{o}(j) & x_{1}(j)
\end{array}\right]
\end{aligned}
$$

Uma vez estimada a estrutura de variância genética para pesos ao $21^{\circ}$ e $42^{\circ}$ dias de idade, a herdabilidade direta da característica foi também estimada para qualquer ponto entre 24 e $30 \%$ de proteína bruta da dieta, da seguinte maneira:

$h_{d_{i}}^{2}=\frac{Z_{i} G Z_{i}^{\prime}}{Z_{i} G Z_{i}^{\prime}+\sigma_{e}^{2}} ;$ em que $i$ representa o nível protéico da dieta.

\section{RESULTADOS E DISCUSSÃO}

Os componentes de covariância estimados dos coeficientes de regressão aleatória e dos resíduos para cada uma das quatro análises realizadas são apresentados na Tab. 3. De modo geral, a variância estimada para o coeficiente de regressão aleatória do intercepto é maior do que a estimada para o coeficiente de regressão aleatória linear. Os dois coeficientes apresentaram, em todas as análises, associação positiva. As correlações entre coeficientes de regressão aleatória do intercepto e o linear do efeito genético aditivo direto foram 0,03 (EV1 21 dias de idade), 0,34 (EV1 - 42 dias de idade), 0,94 (EV2 - 21 dias de idade) e 0,93 (EV2 - 42 dias de idade), com maior associação observada para a linhagem EV2. Este resultado indica que maiores valores genéticos aditivos para peso no ambiente médio (nível protéico igual a zero, numa escala de -1 a 1 ) respondem de maneira positiva ao aumento do nível protéico da dieta. Isso é mais importante para valores genéticos da linhagem EV2 e tem pouca importância para as da linhagem EV1, no $21^{\circ}$ dia de idade.

Normas de reação para 25 codornas, amostradas entre todas as avaliadas, para cada análise, estão representadas na Fig. 1 . No $42^{\circ}$ dia de idade, codornas da linhagem EV1 apresentaram apreciável aumento de dispersão dos valores genéticos com o aumento dos níveis protéicos da dieta. Esse comportamento indica heterogeneidade de sensibilidades de valores genéticos aditivos à mudança ambiental, o que caracteriza a existência de interação genótipo $\mathrm{x}$ ambiente. Porém, no $21^{\circ}$ dia de idade, não se observaram modificações na dispersão dos valores genéticos aditivos em função dos níveis de proteína bruta da dieta. Por sua vez, codornas da linhagem EV2 apresentaram aumento de dispersão dos valores genéticos em função do nível protéico no $21^{\circ}$ e $42^{\circ}$ dia de idade. Os resultados sugerem que a interação genótipo $\mathrm{x}$ ambiente interfere em menores idades na expressão fenotípica da linhagem EV2 comparadas às da linhagem EV1.

Tabela 3. Componentes de variância atribuídos aos coeficientes de regressão do intercepto $\left(b_{0}\right)$ e linear

\begin{tabular}{|c|c|c|c|c|}
\hline & \multicolumn{4}{|c|}{ EV1 } \\
\hline & \multicolumn{4}{|c|}{ Idade } \\
\hline & \multicolumn{2}{|c|}{21} & \multicolumn{2}{|c|}{42} \\
\hline & $b_{0}$ & $b_{1}$ & $b_{0}$ & $b_{1}$ \\
\hline$b_{0}$ & 38,16 & & 257,6 & \\
\hline$b_{1}$ & 0,1592 & 0,7462 & 39,18 & 50,8 \\
\hline \multirow[t]{5}{*}{ Residual } & & & & \\
\hline & \multicolumn{4}{|c|}{ EV2 } \\
\hline & \multicolumn{4}{|c|}{ Idade } \\
\hline & \multicolumn{2}{|c|}{21} & \multicolumn{2}{|c|}{42} \\
\hline & $b_{0}$ & $b_{1}$ & $b_{0}$ & $b_{1}$ \\
\hline$b_{0}$ & 41,83 & & 220,4 & \\
\hline$b_{1}$ & 9.242 & 2.315 & 57,63 & 17,53 \\
\hline Residual & \multicolumn{2}{|c|}{152,5} & \multicolumn{2}{|c|}{475,6} \\
\hline
\end{tabular}
$\left(b_{1}\right)$ do efeito genético aditivo direto em função dos níveis protéicos da dieta e variâncias residuais estimados para as linhagens EV1 e EV2, no $21^{\circ}$ e $42^{\circ}$ dias de idade 
As estruturas de covariância genéticas aditivas diretas estimadas são apresentadas na Fig. 2. A estrutura estimada para a linhagem EV1 no $21^{\circ}$ dia de idade apresenta comportamento coerente com as normas de reação para as codornas amostradas na mesma linhagem e idade. Os valores de variância e covariância não apresentam intensas modificações quando estimados para diferentes idades ou combinações de idades dentro do intervalo considerado. O
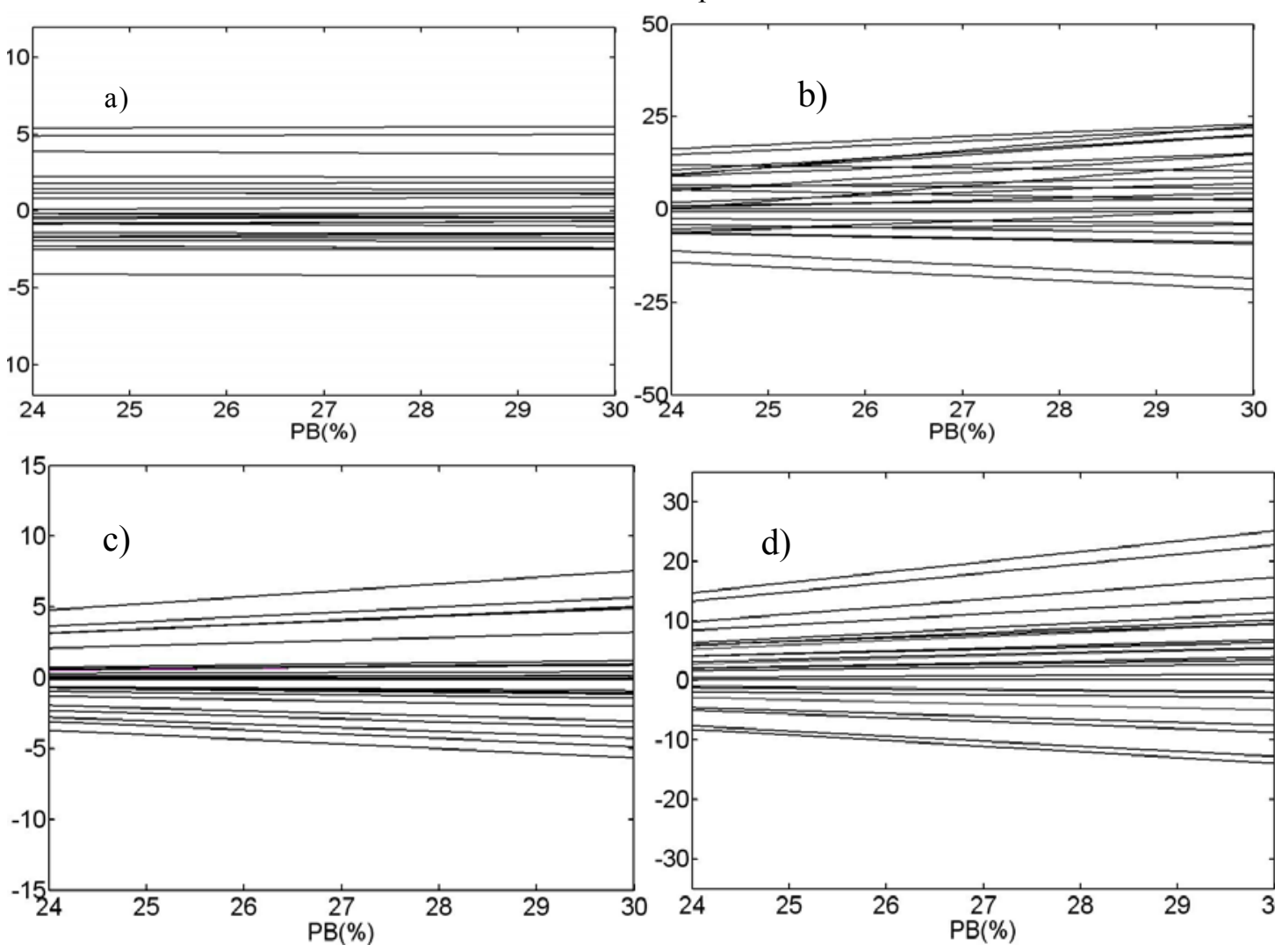

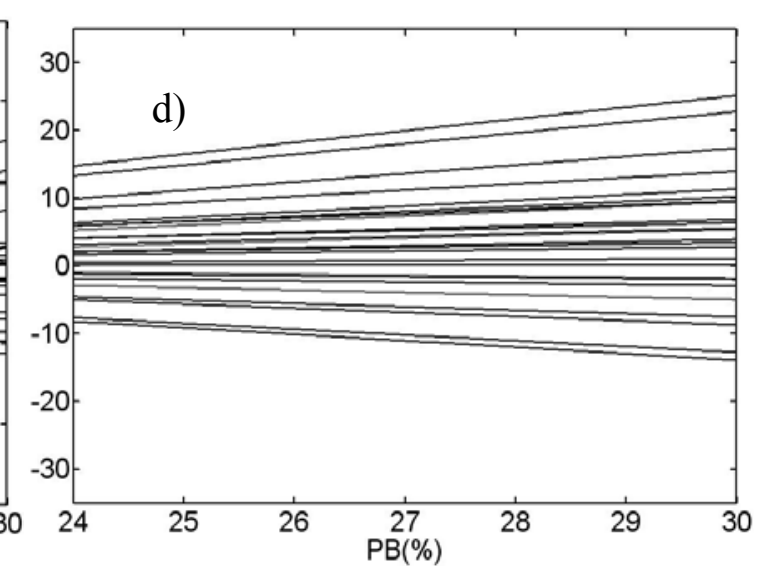

mesmo não foi observado para as estruturas de covariância estimadas para peso no $42^{\circ}$ dia na linhagem EV1, e no $21^{\circ}$ e $42^{\circ}$ dia de idade na linhagem EV2. As superfícies estimadas para essas combinações de idade e linhagem apresentaram intensa inclinação em direção aos maiores valores dos eixos $\mathrm{x}$ e $\mathrm{y}$, indicando maiores valores de covariância para as combinações entre os maiores valores de nível protéico.

Figura 1. Normas de reação de valores genéticos aditivos de 25 indivíduos amostrados aleatoriamente no $21^{\circ}$ e $42^{\circ}$ dias para linhagens EV1 e EV2 (a: EV1-21 dias; b: EV1- 42 dias; c: EV2- 21 dias; d: EV2-42 dias).

As herdabilidades estimadas para todas as combinações de idade e linhagem são apresentadas na Fig. 3. Para as duas linhagens, as herdabilidades estimadas apresentaram maiores valores para pesos no $42^{\circ}$ dia em relação às estimativas para pesos no $21^{\circ}$ dia de idade, o que indica que ocorre crescimento da porção da 

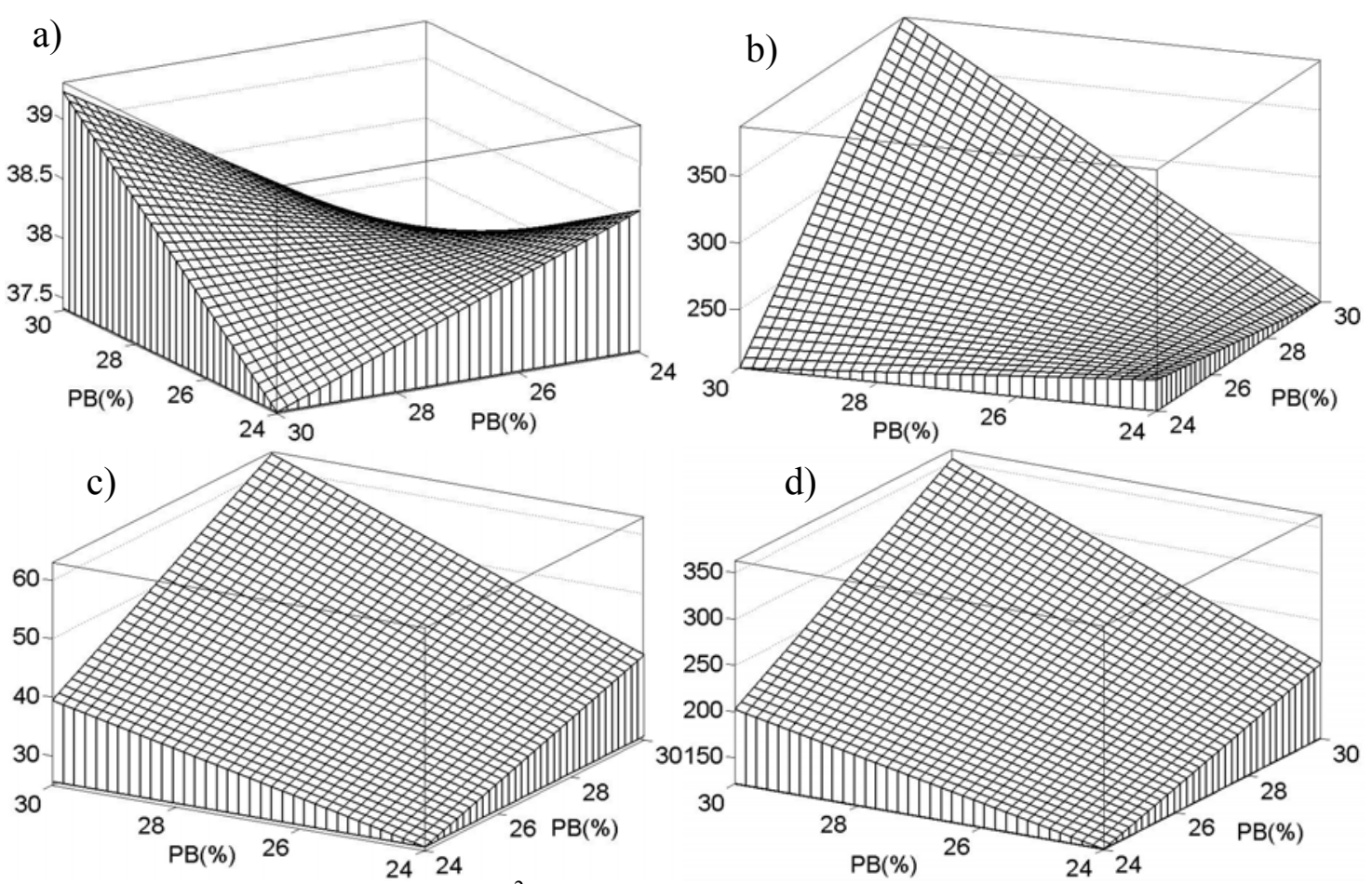

Figura 2. Estruturas de covariância $\left(\mathrm{kg}^{2}\right)$ do efeito genético aditivo direto em função do nível protéico da dieta estimadas no $21^{\circ}$ e $42^{\circ}$ dias, para as linhagens EV1 e EV2 (a: EV1-21 dias; b: EV1- 42 dias; c: EV221 dias; d: EV2-42 dias).

Em razão da homogeneidade de variância genética para diferentes níveis protéicos, a herdabilidade estimada para peso no $21^{\circ}$ dia de idade na linhagem EV1 apresentou valores muito próximos nos diversos níveis protéicos da dieta que variaram de 24 a $30 \%$. As herdabilidades estimadas para as demais combinações de idade e linhagem apresentaram forte variação e maior magnitude para maiores níveis de proteína bruta na dieta, indicando maior resposta à seleção em relação à variância fenotípica.

O comportamento das estruturas de covariância genética e, conseqüentemente, das herdabilidades estimadas para pesos na linhagem EV2 e no $42^{\circ}$ dia de idade na linhagem EV1 indicam que valores genéticos aditivos diretos preditos para diferentes indivíduos apresentam diferentes sensibilidades à modificação do nível protéico da dieta. Para estas situações, avaliações genéticas realizadas em animais que se alimentam com determinado nível protéico na dieta podem produzir predições que não são válidas para outros níveis de proteína bruta da dieta. Dessa maneira, avaliações genéticas com base em informações de indivíduos alimentados com diferentes níveis protéicos seriam necessárias para a predição de valores genéticos de qualidade para diferentes ambientes.

De acordo com Su et al. (2006), modificações na ordem de classificação dos valores genéticos ocorrem quando o valor da correlação entre os coeficientes de regressão aleatória do intercepto e linear é distante da unidade. Os coeficientes de regressão aleatória do intercepto e linear estimados para a linhagem EV2 apresentaram alta correlação entre si, o que indica que, mesmo ocorrendo intensa heterogeneidade de variância, a ordem de classificação dos valores genéticos preditos se altera pouco em diferentes níveis protéicos da dieta. Dessa maneira, avaliações genéticas realizadas sob determinado nível protéico não permitiriam a predição de valores genéticos válidos para outros níveis protéicos, mas os animais de maior valor genético no ambiente de seleção apresentariam superioridade também em outros ambientes do intervalo considerado. 

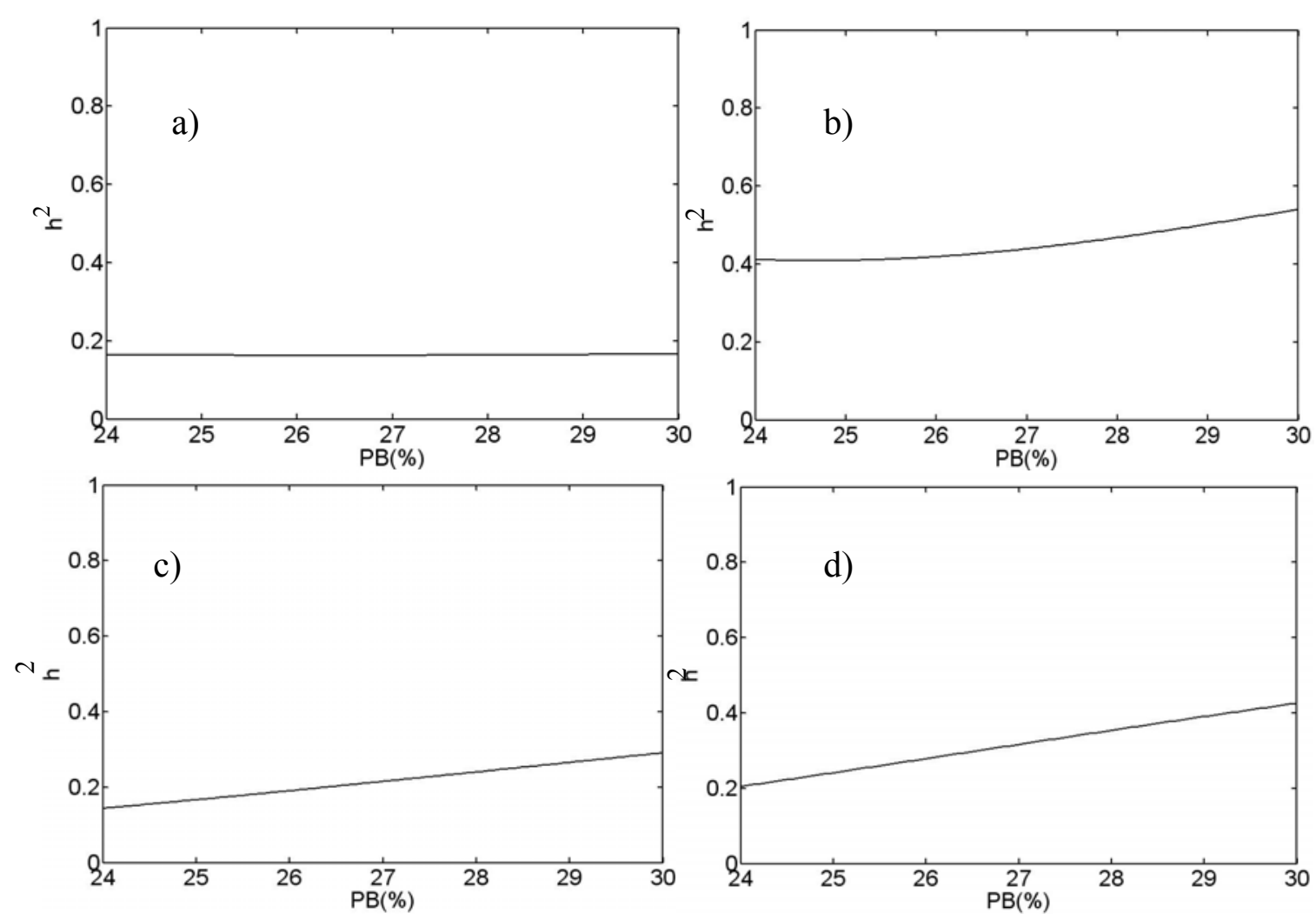

Figura 3. Herdabilidades diretas estimadas para pesos no $21^{\circ}$ e $42^{\circ}$ dias de idade para as linhagens EV1 e EV2, em função do nível protéico da dieta (a- EV1-21 dias; b- EV1- 42 dias; c- EV2- 21 dias; d- EV2-42 dias).

\section{AGRADECIMENTOS}

Ao CNPq, pelo financiamento do projeto.

\section{REFERÊNCIAS BIBLIOGRÁFICAS}

AKBAS, Y.; TAKMA, Ç.; YAYLAK, E. Genetic parameters for quail body weights using a random regression model. S. Afr. J. Anim. Sci., v.34, p104-109, 2004.

CORRÊA, G.S.S.; SILVA, M.A.; FONTES, D.O. et al. Efeito de diferentes níveis de proteína e energia sobre o rendimento de carcaça de codornas européias. Arq. Bras. Med. Vet. Zootec., v.57, p.266-271, 2005.

CORRÊA， G.S.S.; SILVA, M.A.; CORRÊA, A.B. et al. Exigência de metionina + cistina para codornas de corte em crescimento. Arq. Bras. Med. Vet. Zootec., v.58, p.414-420, 2006.
CORRÊA, G.S.S.; SILVA, M.A.; CORRÊA, A.B. et al. Exigência de proteína bruta e energia metabolizável em codornas de corte durante a fase de crescimento. Arq. Bras. Med. Vet. Zootec., v.59, p.488-494, 2007a.

CORRÊA, G.S.S.; SILVA, M.A.; CORRÊA, A.B. et al. Exigência de proteína bruta e energia metabolizável para codornas de corte EV1. Arq. Bras. Med. Vet. Zootec., v.59, p.797-804, 2007 b.

CORRÊA, G.S.S.; SILVA, M.A.; CORRÊA, A.B. et al. Exigências em proteína bruta para codornas de corte EV1 em crescimento. Arq. Bras. Med. Vet. Zootec., v.59, p.1278-1286, 2007c.

CORRÊA, G.S.S.; SILVA, M.A.; CORRÊA, A.B. et al. Desempenho de codornas de corte EV1 alimentadas com diferentes níveis de lisina na dieta. Arq. Bras. Med. Vet. Zootec., v.59, p.1545-1553, 2007d.

DIONELlO, N.J.L.; SILVA, M.A.; CORREA, G.S.S. Genetic evaluation of european quail by 
random regression analysis In: WORLD CONGRESS ON GENETICS APPLIED TO LIVESTOCK PRODUCTION, 8,, 2006, Belo Horizonte. Procedings... Belo Horizonte, 2006.

FALCONER, D. S. Introduction to quantitative genetics. Essex: Longman Scientific \& Technical, 1989. 438p.

FERREIRA, I.C.; CORREAA, G.S.S.; SILVA, M.A. et al. Análise de custo de experimentos realizados com diferentes grupos genéticos de codornas de corte alimentadas com dietas com diferentes níveis de proteína bruta e energia metabolizável. In: REUNIÃO ANUAL DA SOCIEDADE BRASILEIRA DE ZOOTECNIA, 41., 2004, Campo Grande. Anais..., Campo Grande-MS: SBZ, 2004.

FRIDRICH, A.B.; VALENTE, B.D.; SILVA, A.F. et al. Exigência de proteína bruta para codornas européias no período de crescimento. Arq. Bras. Med. Vet. Zootec., v.57, p.261-265, 2005.

KIRKPATRICK, M.; LOFSVOLD, D.; BULMER, M.; Analysis of the inheritance, selection and evolution of growth trajectories. Genetics, v.124, p.979-993, 1990.
KOLMODIN, R.; STRANDBERG, E.; MADSEN, P. et al. Genotype by environment interaction in nordic dairy cattle studied using reaction norms. Acta Agric. Scand., Sec A, Anim. Sci., v.52, p.11-24, 2002.

MISZTAL, REMLF90 Manual: Disponível em: $<$ http://nce.ads.uga.edu/ ignacy/numpub/blupf90 /docs/remlf90.pdf $>$, 2001, Acessado em: 13 set 2006.

SAATCI, M.; OMED, H.; AP DEWI, I. Genetic Parameters from Univariate and Bivariate Analyses of Egg and Weight Traits in Japanese Quail. Poult. Sci., v.85, p.185-190, 2006.

SU, G.; MADSEN P.; LUND M. S. et al. Bayesian analysis of the linear reaction norm model with unknown covariates. J. Anim. Sci., v.84, p.1651-1657, 2006.

VALENTE, B.D.; CORRÊA, G.S.S.; DIONELLO, N.L. et al. Interaction between methionine of diet and genotype in meat type quail. In: WORLD CONGRESS ON GENETICS APLIED TO LIVESTOCK PRODUCTION, 8., 2006, Belo Horizonte. Proceedings... Belo Horizonte, 2006. 